\title{
Seasonal Pattern of Peptic Ulcer Perforation in Central Anatolia
}

\author{
Fatih Dal ${ }^{1}$, Ugur Topal ${ }^{2}$ \\ ${ }^{1}$ Department of General Surgery, Erciyes University,Melikgazi, Kayseri, Turkey, \\ ${ }^{2}$ Department of Surgical Oncology, Erciyes University, Melikgazi, Kayseri, Turkey.
}

\section{ABSTRACT}

\section{BACKGROUND}

Previous studies have reported seasonal variations in peptic ulcer disease (PUD), but only few large-scale, population-based studies have been conducted in this regard. In this study, we wanted to present the seasonal relationship of peptic ulcer perforation admissions, seasonal variation of its incidence, modes of surgical management, the seasonal distribution of postoperative severe complications and the patient outcome.

\section{METHODS}

This is a retrospective cohort study. Patients hospitalized for peptic ulcer perforation between $1^{\text {st }}$ January 2008 and $1^{\text {st }}$ January 2020 were included in the study. The patients were divided into two groups according to postoperative complication status as Group1 - Clavien Dindo $<3$ and Group 2 - Clavien Dindo $>3$. Age, gender and seasonal periods were compared. In addition, patients were divided into three groups according to age as 18 - 40 yrs., 40 - 60 yrs. and over 60 yrs. The gender and complication status of the patients were also evaluated in seasonal groups.

\section{RESULTS}

135 patients participated in our study. Group 1 constituted of 107 patients and Group 2 constituted of 28 patients. Admission to the hospital due to peptic ulcer perforation was most common in spring (29.6\%) and summer (29.6\%). Twenty - eight patients had Clavien - Dindo 3 or more complications. The mean age was higher in Group 2 (70.78 vs $50.2 \mathrm{P}: 0.001$ ) as well as female gender dominancy ( $60.7 \%$ vs $29.9 \%$ ). In Group 2 winter months were more frequent (46,5\% vs $21.5 \%$ ); however, there was no significant difference between the seasons and the complication groups. In Group 2 , female gender was more common in winter (21.7 \% vs $69.2 \%$ P:0.005) and autumn season (31.3\% vs $100 \% \mathrm{P}:$ : 0.027).

\section{CONCLUSIONS}

In our study, we found an increased incidence of peptic ulcer perforation in spring and summer. For patients at higher risk, an appropriate pharmacological treatment can be arranged to reduce the risk of perforation during the risky season.

\section{KEY WORDS}

Peptic Ulcer Disease, Seasonal Change, Complication
Corresponding Author: Dr. Uğur Topal. MD Department of General Surgery, Erciyes University, Faculty of Medicine, 38030, Melilgazi/Kayseri, Turkey. E-mail: sutopal2005@hotmail.com

DOI: $10.14260 / j e m d s / 2021 / 501$

How to Cite This Article: Dal F, Topal U. Seasonal pattern of peptic ulcer perforation in Central Anatolia. J Evolution Med Dent Sci 2021;10(31):24512455, DOI: 10.14260/jemds/2021/501

Submission 02-05-2021, Peer Review 06-07-2021, Acceptance 13-07-2021, Published 02-08-2021.

Copyright @ 2021 Fatih Dal et al. This is an open access article distributed under Creative Commons Attribution License [Attribution 4.0 International (CC BY 4.0)] 


\section{BACKGROUND}

Peptic ulcer is a disease of very large human population caused by an imbalance between aggressive factors such as stomach acid pepsin and mucosal defense. The incidence of peptic ulcers have fluctuated considerably in the past. There was a rapid increase in its prevalence at the turn of the 20th century in the western countries. This has been followed by a notable decline in their incidence and prevalence over the past four decades. ${ }^{1}$

With the discovery and treatment of Helicobacter pylori $(H$. pylori), the incidence of gastric or duodenal peptic ulcer disease (PUD) has declined in recent years. However, the incidence of peptic ulcer complications has not decreased as expected. Bleeding and perforation are the most serious complications of PUD. Results of ulcer bleeding have improved due to advances in endoscopic and interventional radiological techniques. Perforation is responsible for most PUD - related deaths, although bleeding is a more common complication. Perforated peptic ulcer surgery is an emergency and is associated with short term mortality in up to $30 \%$ of patients and morbidity up to $50 \%$. The cause of the perforation is unclear, but smoking, alcohol, non steroidal antiinflammatory drug (NSAID) medication, and H. Pylori infection have been identified as facilitating factors in many publications The factors that could be associated with mortality and morbidity in this group of patients have been the subject of many retrospective and prospective studies. Age, gender, type of surgery, chronic disease, drug and alcohol use, duration of perforation, blood pressure, concomitant disease, renal failure, and liver cirrhosis have been detected as the factors associated with morbidity in various publications. 2,3

The seasonal relationship of many diseases that require urgent surgery in general surgery practice has been previously demonstrated. 4,5 Although a possible seasonality for PUD has been extensively investigated, there is no consensus as to the peak season(s) of greatest acute disease activity. PUD is not a single entity, as it may be categorized according to the lesion site, i.e., stomach or duodenum, and presence or absence of complications, i.e., hemorrhage or perforation. Some studies have focused on PUD, GU or DU, and others on complicated ulcers, while several studies have the limitation to be based on small sample size population. The seasonal relationship in the occurrence of ulcer disease has been described as more frequent in winter and a decrease in summer months in most studies conducted in different countries. ${ }^{6-8}$

In some studies, it has been shown that there were two peaks in spring and autumn. ${ }^{9}$ In a large scale study conducted by Roberto Manfredini et al. in Italy, ${ }^{10}$ three distinct peaks were identified in spring, autumn, and winter. Studies in the literature are generally old, but include all applications due to peptic ulcer. Current studies focusing on perforation in the literature originate from 3rd World countries such as Africa and India.11-14 There are a few studies on this subject in our country. ${ }^{15}$ However, this possible seasonal pattern has not been fully revealed in our country yet.

In this study, we wanted to present the seasonal relationship of peptic ulcer perforation admissions as well as the seasonal distribution of postoperative severe complications in the light of the literature.

\section{METHODS}

This is a retrospective cohort study. Patients with peptic ulcer perforation who underwent surgical treatment at Erciyes University between January 1, 2008 and January 1, 2019 were included in the study. Tumor perforations, traumatic perforations, and patients under 18 years of age were excluded from the study. A database was created including hospital registry data, patient follow up files and pathology data. Patients were analyzed using this database. Ethics committee approval was received for this study from the ethics committee of Erciyes University Faculty of Medicine.

Patients were compared with seasonal groups in terms of age, gender, and postoperative complications. The patients were divided into two groups, Group 1: Clavien Dindo $<3$ and Group 2: Clavien Dindo $>3$, based on Clavien - Dindo scoring system for postoperative complications. Clavien Dindo 3 means requiring surgical, endoscopic or radiological intervention. In addition, patients were divided into three groups according to age as 18 - 40, 40 - 60 and over 60 yrs. The gender and postopearative complications of the patients were also examined in season groups.

Kayseri, the province where our study was carried out, is located in the Middle Kizılırmak section where the southern part of Central Anatolia and the Taurus Mountains come close to each other. It is located between 37 degrees 45 minutes and 38 degrees 18 minutes north latitudes and 34 degrees 56 minutes to 36 degrees 58 minutes east longitudes. The altitude of the city center is 1054 meters. Many parts of the province of Kayseri have steppe climate characteristics. Summers are hot and dry, winters are cold and snowy. We provided the weather data of cities from the Turkish state meteorological service (http: / / www.mgm.gov.tr / veridegerlendirme / il ve ilceler - ista tistik.aspx). Seasons are defined in Northern Hemisphere as: Winter (December - February), Spring (March - May), Summer (June - August) and Autumn (September - November).

Informed consent could not be obtained because the study was retrospective.

\section{Surgical Method}

The operations performed were carried out by different surgical teams using the graham style rafi method. A biopsy was taken routinely from each patient who was taken for operation and underwent graham procedure. At a distance of $1-1.5 \mathrm{~cm}$ from the edge of the perforation, 3 or 4 pieces of 000 silk sutures(Doğsan, İstanbul) were passed and an intact vascular pedicled omentum was placed in between, or the sutures were tied first, then the omentum was placed between the silk. After the ulcer was closed, the peritoneal cavity was cleared.

Then, the entire abdominal cavity was irrigated with 5 liters of warm saline. Drains were used in cases with debridement due to diffuse fibrinous exudate, purulent fluid and contaminated local collections.

\section{Statistical Evaluation}

SPSS 23.0 package program was used for the statistical analysis of the data. Categorical measurements were summarized as numbers and percentages, continuous 
measurements as mean and standard deviation (median and minimum - maximum where necessary). chi-square and Fisher's exact tests were used to determine the differences in categorical variables between groups. In the comparison of continuous measurements between groups, the distributions were controlled and the Mann-Whitney $u$ test was used in paired groups for parameters that did not show normal in all tests.

\section{RESULTS}

135 patients participated in our study. Male gender was more common (63.7\% versus $36.3 \%$ ). Admission due to peptic ulcer was more frequent in spring (29.6\%) and summer 29.6 $\%)$. It was found more frequently in the population over the age of 60 yrs. (45.2\%). These are shown in Table 1.

\begin{tabular}{|c|c|c|}
\hline \multicolumn{2}{|c|}{ Measurements } & $\begin{array}{c}\text { Peptic Ulcer Perforation } \\
\text { Admissions }\end{array}$ \\
\hline \multicolumn{2}{|c|}{ Age ((Mean + SD) (min - max)) } & $54,50 \pm 20,28$ \\
\hline \multirow{2}{*}{$\operatorname{Sex}(N, \%)$} & Male & $\begin{array}{c}55(18-91) \\
86(63,7)\end{array}$ \\
\hline & Female & $49(36,3)$ \\
\hline \multirow{4}{*}{ Season $(\mathrm{N}, \%)$} & Winter & $36(26,7)$ \\
\hline & Spring & $40(29,6)$ \\
\hline & Summer & $40(29,6)$ \\
\hline & Autumn & $19(14,1)$ \\
\hline \multirow{3}{*}{ Age groups $(\mathrm{N}, \%)$} & Between $18-39$ & $35(25,9)$ \\
\hline & Between $40-60$ & $39(28,9)$ \\
\hline & 61 and above & $61(45,2)$ \\
\hline
\end{tabular}

Twenty-eight patients had Clavien - Dindo 3 and more complications. In Group 2, the mean age was higher (70.78 vs 50.2 P : 0.001). In Group 2, female gender was dominant (60.7 $\%$ vs $29.9 \%$ ). Winter season was more frequent in Group 2 ( $46.5 \%$ vs $21.5 \%$ ), but there was no significant difference between the complication groups in terms of seasons. These distribution. The statistical significance level was taken as 0.05

are shown in Table 2. Our mortality rate was $12.5 \%$ and its distribution was in Winter (N: 8, 47.1\%), Summer (N: 4, 23.5

\%) Spring (N: 3, $17.6 \%$ ), autumn (N: 2, $11.8 \%$ ) P: 0.231 .

In Group 2, females were more common in winter $(21.7 \%$ vs $69.2 \%$ P: 0.005$)$ and in the autumn season (31.3\% vs 100 $\%$ P: 0.027). In Group 2, the median age was higher in winter (46 vs $80 \mathrm{P}: 0.001$ ) and in summer it was higher (51 vs $71 \mathrm{P}$ : 0.042). They are shown in Table 3.

\begin{tabular}{|c|c|c|c|c|}
\hline \multicolumn{2}{|c|}{ Measurements } & Group 1 & Group 2 & $\mathbf{P}^{*}$ \\
\hline \multicolumn{2}{|c|}{ Age [( Mean + SD) (min - max)] } & $\begin{array}{c}50,20 \pm 19,20 \\
50(17-91)\end{array}$ & $\begin{array}{c}70,78 \pm 15,67 \\
74(35-90)\end{array}$ & 0,001 \\
\hline \multirow{2}{*}{$\operatorname{Sex}(N, \%)$} & Male & $75(70,1)$ & $11(39,3)$ & \multirow{3}{*}{0,003} \\
\hline & Female & $32(29,9)$ & $17(60,7)$ & \\
\hline \multirow{4}{*}{ Season $(\mathrm{N}, \%)$} & Winter & $23(21,5)$ & $13(46,4)$ & \\
\hline & Spring & $34(31,8)$ & $6(21,4)$ & \multirow{3}{*}{0,070} \\
\hline & Summer & $34(31,8)$ & $6(21,4)$ & \\
\hline & Autumn & $16(15,0)$ & $3(10,7)$ & \\
\hline \multirow{3}{*}{$\begin{array}{l}\text { Age groups } \\
\quad(\mathrm{N}, \%)\end{array}$} & Between 18 - & $34(31,8)$ & $1(3,6)$ & \multirow{3}{*}{0,001} \\
\hline & Between $40-60$ & $34(31,8)$ & $5(17,9)$ & \\
\hline & 61 and above & $39(36,4)$ & $22(78,6)$ & \\
\hline \multicolumn{5}{|c|}{$\begin{array}{l}\text { Table 2. Seasonal Variation of Peptic Ulcer } \\
\text { Perforation for Clavien Dindo Groups }\end{array}$} \\
\hline
\end{tabular}

\begin{tabular}{|c|c|c|c|c|}
\hline \multicolumn{2}{|c|}{ Measurements } & \multirow{2}{*}{$\begin{array}{c}\text { Grup 1 } \\
18(78,3)\end{array}$} & \multirow{2}{*}{$\begin{array}{l}\text { Grup 2 } \\
4(30,8)\end{array}$} & \multirow{3}{*}{$\begin{array}{c}\mathrm{P}^{*} \\
\mathbf{0 , 0 0 5}\end{array}$} \\
\hline Winter $(\mathrm{N} 0 \%$ & Male & & & \\
\hline Winter $(\mathrm{N}, \%)$ & Female & $5(21,7)$ & $9(69,2)$ & \\
\hline \multirow{2}{*}{ Spring (N, \%) } & Male & $19(55,9)$ & $4(66,7)$ & \multirow[b]{2}{*}{0,622} \\
\hline & Female & $15(44,1)$ & $2(33,3)$ & \\
\hline \multirow{2}{*}{ Summer (N, \%) } & Male & $27(79,4)$ & $3(50,0)$ & \multirow{2}{*}{0,125} \\
\hline & Female & $7(20,6)$ & $3(50,0)$ & \\
\hline \multirow{2}{*}{ Autumn (N, \%) } & Male & $11(68,8)$ & $0(0,0)$ & \multirow[b]{2}{*}{0,027} \\
\hline & Female & $5(31,3)$ & $3(100)$ & \\
\hline \multirow{4}{*}{$\begin{array}{c}\text { Season \& Age } \\
(\mathrm{N}, \%)\end{array}$} & Winter & $46(19-85)$ & $80(45-90)$ & 0,001 \\
\hline & Spring & $56(20-91)$ & $73(35-74)$ & \multirow{4}{*}{$\begin{array}{l}0,251 \\
0,042 \\
0,179\end{array}$} \\
\hline & Summer & $51(17-76)$ & $71(43-89)$ & \\
\hline & Autumn & $47,5(18-78)$ & $70(48-75)$ & \\
\hline \multirow{3}{*}{ Winter $(\mathrm{N}, \%)$} & $18-39$ & $8(34,8)$ & $0(0,0)$ & \\
\hline & $40-60$ & $6(26,1)$ & $1(7,7)$ & \multirow[t]{2}{*}{0,007} \\
\hline & 61 and above & $9(39,1)$ & $12(92,3)$ & \\
\hline \multirow{3}{*}{ Spring (N, \%) } & $18-39$ & $11(32,4)$ & $1(16,7)$ & \multirow{4}{*}{0,509} \\
\hline & $40-60$ & $9(26,4)$ & $1(16,7)$ & \\
\hline & 61 and above & $14(41,2)$ & $4(66,6)$ & \\
\hline \multirow{3}{*}{ Summer (N, \%) } & $18-39$ & $11(32,4)$ & $0(0,0)$ & \\
\hline & $40-60$ & $12(35,3)$ & $2(33,3)$ & \multirow[t]{2}{*}{0,170} \\
\hline & 61 and above & $11(32,4)$ & $4(66,7)$ & \\
\hline \multirow{3}{*}{ Autumn (N, \%) } & $18-39$ & $4(25,0)$ & $0(0,0)$ & \multirow{3}{*}{0,433} \\
\hline & $40-60$ & $7(43,8)$ & $1(33,3)$ & \\
\hline & 61 and above & $5(31,3)$ & $2(66,7)$ & \\
\hline
\end{tabular}

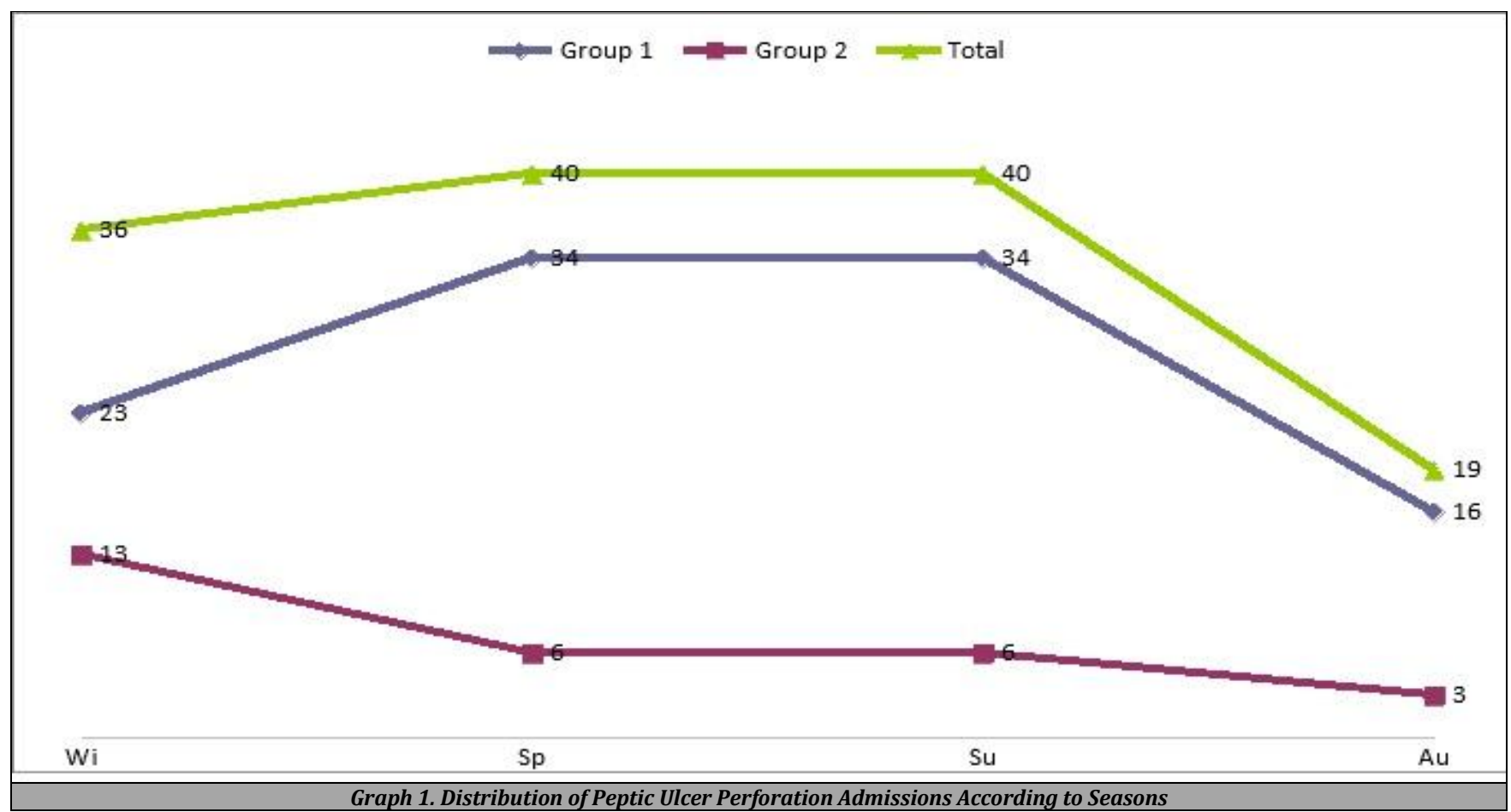




\section{DISCUSSION}

Peptic ulcer disease (PUD) is caused by an imbalance between stomach acid - pepsin and mucosal defense barriers. It affects 4 million people worldwide each year. The incidence of PUD is estimated to be about $1.5 \%$ to $3 \% .{ }^{16,17}$ Although there are many peptic ulcer preventive drugs that have recently come into use, ulcer perforation is still one of the most common complications of peptic ulcer due to the widespread use of NSAIDs, steroid drugs and especially by the elderly group. ${ }^{18}$

Experimental studies have shown that many factors in the gastrointestinal tract, including gastric $\mathrm{pH}$, digestive enzymes, mucosal cell replication, and blood flow, have a specific temporal organization showing circadian rhythms.19,20 Although the seasonal variation of peptic ulcer disease has been extensively investigated in two large studies conducted in the USA ${ }^{21}$ and China ${ }^{22}$ studies other than this study have limited effects due to the small sample size.

The seasonal variation in peptic ulcer disease has been extensively studied in the literature. Autumn and winter peaks were reported in the study conducted in Germany and in the studies conducted in the USA and Italy.21,23,24 Bleeding due to peptic ulcer was found in Russia and Japan more in autumn or winter. ${ }^{25,26}$

Thomopoulos et al. found an increase in the rate of PUD in summer and autumn in Greece. ${ }^{27}$ Lopez - Cepero et al. could not find seasonality in Spain. ${ }^{28} \mathrm{An}$ increasing seasonal change has been reported in the spring and summer months in Australia and Poland. ${ }^{29,30}$ On the other hand, in a study conducted in Turkey, during the winter months peptic ulcer perforation was significantly higher. ${ }^{15}$ In our series, peptic ulcer perforation seems to have had two peaks in spring and summer.

There are several factors that are claimed to play a role in the seasonality of peptic ulcer disease. Liu et al. found a close relationship between peptic ulcer disease, average temperature, average highest and lowest temperature, and average atmospheric pressure. ${ }^{31}$ Seasonality of $H$. pylori infection can be considered as another possible factor that may affect peptic ulcer disease. ${ }^{32}$ Corticosteroids and nonsteroidal anti inflammatory drugs are important factors in peptic ulcer development, but it is unclear whether they play a role in the seasonal pattern of peptic ulcer disease or not. Theoretically, the seasonally changing incidence of inflammatory and rheumatic diseases and increasing drug use due to this incidence may indirectly affect peptic ulcer disease. The use of alcohol, another ulcerogenic substance, differs in societies. Changing alcohol consumption rates for the seasons may also have an indirect effect. ${ }^{10}$ As a result of fluctuating temperatures in cold seasons, the sympathetic nervous system is stimulated in the human body, resulting in vasoconstriction in blood vessels and this causes mucosal damage. ${ }^{33}$ We could not fully reveal the mechanism that creates seasonal differences in our series. There was probably a multi factorial impact.

The postoperative morbidity rate in peptic ulcer perforation varies between 21 and $42 \%$ in the literature. The most common complications are related to the pulmonary system and appear as wound infections. ${ }^{1}$ In the study they conducted, Taş I et al. found that for those over the age of
$60 \mathrm{yrs}$., the presence of comorbid diseases and the perforation diameter were associated with postoperative complications. ${ }^{1}$ Similarly, Kim et al. found that being over 60 years old and also being females constituted a risk factor. ${ }^{34}$ In the study they conducted at the center having similar climatic conditions to our region in Turkey, Kocer B et al. found the distribution of admissions similar between seasons in patients operated on for peptic ulcer perforation, but postoperative morbidity and mortality rates increased in winter months. ${ }^{15}$ Similarly, although the complication rates were high during the winter months in our study, there was no significant relationship. In our study, postoperative complications were associated with advanced age, and the rate increased, especially in the group over 60 years old. In our study, complications were observed more frequently in female gender in winter and autumn seasons.

Postoperative mortality is the most serious complication after peptic ulcer perfusion. A mortality rate varying between $1.3 \%$ and $20 \%$ has been reported in the literature, but there are also studies reporting this rate as a 90 - day mortality rate of up to $30 \%$ because the definition of postoperative mortality is different in the guidelines. The most important risk factors for postoperative mortality are the presence of shock at hospitalization, comorbid diseases, female gender, smoking and advanced age. Mortality rate in elderly patients who underwent surgery for peptic ulcer perfusion increased from $12 \%$ to $47 \% .15,18,35$

In our patient population, elderly patients were more common, and since our center is a tertiary reception hospital, the duration of surgical treatment was naturally prolonged for patients who came from external centers. Despite such risk factors, our postoperative mortality rate was $12.5 \%$. We could not find seasonal correlation with the development of mortality, but it was higher in the winter season.

\section{CONCLUSIONS}

PUD still continues to be a serious problem in terms of morbidity and mortality, especially in elderly patients. In addition, delay in diagnosis and treatment and presence of additional diseases are other important causes of morbidity and mortality. Some previous studies reported a seasonal pattern for acute PUD. In our study, admission to the hospital due to peptic ulcer perforation peaked in spring and autumn. There was no relationship between severe postoperative morbidities and the seasons. Female gender and advanced age were associated with morbidity. Complications were more frequent in female gender in winter and autumn. Our current knowledge is not sufficient to reveal the reasons for these seasonal relationships. Multi center studies with similar climate properties are needed on this subject. Although this study does not provide insight into pathogenetic factors, the possible demonstration of seasonal variation in PUD hospital admissions may prompt further research to better understand seasonality and guide appropriate management.

Data sharing statement provided by the authors is available with the full text of this article at jemds.com.

Financial or other competing interests: None. 
Disclosure forms provided by the authors are available with the full text of this article at jemds.com.

\section{REFERENCES}

[1] Taş İ, Ülger BV, Önder A, et al. Risk factors influencing morbidity and mortality in perforated peptic ulcer disease. Ulus Cerrahi Derg 2014;31(1):20-5.

[2] Dadfar A, Edna TH. Epidemiology of perforating peptic ulcer: a population-based retrospective study over 40 years. World J Gastroenterol 2020;26(35):5302-13.

[3] Tarasconi A, Coccolini F, Biffl WL, et al. Perforated and bleeding peptic ulcer: WSES guidelines. World J Emerg Surg 2020;15:3

[4] Gok M, Topal U, Oz AB, et al. Seasonal pattern of acute appendicitis in central anatolia. Erciyes Med J 2020;42(2):207-13.

[5] Zangbar B, Rhee P, Pandit V, et al. Seasonal variation in emergency general surgery. Ann Surg 2016;263(1):7681.

[6] Fich A, Goldin E, Zimmerman J, et al. Seasonal variations in the frequency of endoscopically diagnosed duodenal ulcer in Israel. J Clin Gastroenterol 1988;10(4):380-2.

[7] Linn HW. An analysis of peptic ulcer in South Australia, based on a study of 1,027 case reports. Med J Aust 1946;2(19):649-58.

[8] Breen FJ, Grace WJ. Bleeding peptic ulcer: seasonal variation. Am J Dig Dis 1962;7:727-32.

[9] Christensen A, Hansen CP, Thagaard C, et al. Seasonal periodicity of perforated gastric ulcer. Dan Med Bull 1988;35(3):281-2.

[10] Manfredini R, De Giorgio R, Smolensky MH, et al. Seasonal pattern of peptic ulcer hospitalizations: analysis of the hospital discharge data of the Emilia-Romagna region of Italy. BMC Gastroenterol 2010;10:37.

[11] Bupicha JA, Gebresellassie HW, Alemayehu A. Pattern and outcome of perforated peptic ulcer disease patient in four teaching hospitals in Addis Ababa, Ethiopia: a prospective cohort multicenter study. BMC Surg 2020;20(1):135.

[12] Lal JS, Channadasar S. Risk factors and seasonal trends of duodenal ulcer perforation. Int Surg J 2016;3(2):876-8.

[13] Agbonrofo PI, Irowa 00, Okhakhu AL, et al. Seasonal variation of gastro-duodenal perforation in university of benin teaching hospital (UBTH)-a 5 years study. Clin Surg 2018;3:2064.

[14] Bekele A, Zemenfes D, Kassa S, et al. Patterns and seasonal variations of perforated peptic ulcer disease: experience from ethiopia. Annals of Afri Surg 2017;14(2);86-91.

[15] Kocer B, Surmeli S, Solak C, et al. Factors affecting mortality and morbidity in patients with peptic ulcer perforation. J Gastroenterol Hepatol 2007;22(4):565-70.

[16] Zelickson MS, Bronder CM, Johnson BL, et al. Helicobacter pylori isnot the predominant etiology for peptic ulcers requiring operation. Am Surg 2011;77(8):1054-60.

[17] Zittel TT, Jehle EC, Becker HD. Surgical management of peptic ulcer disease today--indication, technique and outcome. Langenbecks Arch Surg 2000;385(2):84-96.

[18] Chung KT, Shelat VG. Perforated peptic ulcer-an update. World J Gastrointest Surg 2017;9(1):1-12.
[19] Tarquini B, Vener KJ. Temporal aspects of the pathophysiology of human ulcer disease. Chronobiol Int 1987;4(1):75-89.

[20] Moore JG, Smolensky M. Biological rhythms in gastrointestinal function and processes: implications for the pathogenesis and treatment of peptic ulcer disease. In: Ulcer Disease. Investigation and Basis for Therapy 1991: p. 55-85.

[21] Sonnenberg A, Wasserman IH, Jacobsen SJ. Monthly variation of hospital admission and mortality of peptic ulcer disease: a reappraisal of ulcer periodicity. Gastroenterology 1992;103(4):1192-8.

[22] Liu D, Gao A, Tang G, et al. Study of the relationship between the onset of peptic ulcers and metereological factors. Chin Med J (Engl) 2003;116(12):1940-2.

[23] Scholtyssek S, Allmendinger G, Blaich E, et al. Seasonal incidence of duodenal ulcer-a myth? Z Gastroenterol 1986;24(4):175-8.

[24] Savarino V, Mela GS, Zentilin P, et al. Are duodenal ulcer seasonal fluctuations paralleled by seasonal changes in 24-hour gastric acidity and helicobacter pilori infection? J Clin Gastroenterol 1996;22(3):178-81.

[25] Tishchenko AM, Brusnitsyna MP, Boiko VV. The seasonality of acute hemorrhages in gastroduodenal ulcers. Vrach Delo 1990;5:11-4.

[26] Nomura T, Ohkusa T, Araki A, et al. Influence of climatic factors in the incidence of upper gastrointestinal bleeding. J Gastroenterol Hepatol 2001;16(6):619-23.

[27] Thomopoulos KC, Katsakoulis EC, Margaritis VG, et al. Seasonality in the prevalence of acute upper gastrointestinal bleeding. J Clin Gastroenterol 1997;25(4):576-9.

[28] Lopez-Cepero JM, Lopez-Silva ME, Amaya-Vidal A, et al. Influence of climatic factors on the incidence of upper gastrointestinal bleeding. Gastroenterol Hepatol 2005;28(9):540-5.

[29] Adler J, Ingram D, House T. Perforated peptic ulcer--a seasonal disease? Aust N Z J Surg 1984;54(1):59-61.

[30] Wysocki A, Kaminski W, Krzywon J. Seasonal periodicity of perforated peptic ulcers. Przegl Lek 1999;56(3):18991.

[31] Liu DY, Gao AN, Tang GD, et al. Relationship between onset of peptic ulcer and meteorological factors. World J Gastroenterol 2006;12(9):1463-7.

[32] Yuan XG, Xie C, Chen J, et al. Seasonal changes in gastric mucosal factors associated with peptic ulcer bleeding. Exp Ther Med 2015;9(1):125-30.

[33] Fares A. Global patterns of seasonal variation in gastrointestinal diseases. J Postgrad Med 2013;59(3):203-7.

[34] Kim JM, Jeong SH, Lee YJ et al. Analysis of risk factors for postoperative morbidity in perforated peptic ulcer. J Gastric Cancer 2012;12(1):26-35.

[35] Buck DL, Møller MH, Danish Clinical Register of Emergency Surgery. Influence of body mass index on mortality after surgery for perforated peptic ulcer. Br J Surg 2014;101(8):993-9. 